\title{
Doenças foliares e o controle por fungicidas na produtividade e qualidade de grãos de trigo
}

\author{
Lucas Navarini ${ }^{1}$, Ricardo Silveiro Balardin ${ }^{2}$
}

${ }^{1}$ Fundação centro de experimentação e pesquisa fecotrigo (FUNDACEP FECOTRIGO). RS 342 km 149 Cx. Postal 10. CEP: 98.005-970 Cruz Alta, RS, Brasil. ${ }^{2}$ Universidade Federal de Santa Maria (UFSM), Santa Maria, RS, Brasil.

Autor para correspondência: Lucas Navarini (navarini@gmail.com)

Data de chegada: 22/10/2010. Aceito para publicação em: 17/09/2012.

\section{RESUMO}

Navarini, L.; Balardin, R.S. Doenças foliares e o controle por fungicidas na produtividade e qualidade de grãos de trigo. Summa Phytopathologica, v.38, n.4, p.294-299, 2012.

O estudo foi estruturado no intuito de determinar os fatores, do ponto de vista do manejo químico de doenças foliares, necessários para obtenção de trigo com qualidade de panificação. $\mathrm{O}$ experimento em blocos ao acaso com seis repetições buscou esclarecer a interação entre doze cultivares e sete programas de aplicação de fungicidas e suas implicações na produtividade e qualidade de grãos de trigo. Os resultados obtidos mostraram que os efeitos proporcionados pelos fungicidas, no controle de doenças, e seus efeitos diretos na fisiologia de plantas de trigo, foram fatores determinantes para obtenção de trigo com alta qualidade. Mostrando, também que as doenças comprometem a remobilização do nitrogênio das folhas para os grãos. Ficaram evidentes as diferenças entre estrobilurinas e triazóis no controle de manchas foliares e de ferrugem da folha, onde os fungicidas triazóis foram mais eficientes no controle do complexo de manchas foliares, quando comparados as estrobilurinas. Porém, o controle efetivo da ferrugem da folha do trigo foi proporcionado pelas estrobilurinas. Os estádios fenológicos do elongamento e emissão de espigas são momentos críticos para o controle químico de manchas foliares em condições de monocultura. E a aplicação de fungicidas após o florescimento é imprescindível para o adequado manejo da ferrugem da folha.

Palavras-chave adicionais: força de glúten, estrobilurinas, nitrogênio, Triticum sativum, Puccinia recondita, manchas foliares.

\section{ABSTRACT}

Navarini, L.; Balardin, R.S. Foliar diseases and control by fungicides on yield and quality of wheat grains. Summa Phytopathologica, v.38, n.4, p.294-299, 2012.

The study was structured to determine the necessary factors, from the point of view of chemical control of foliar diseases, to obtain high quality wheat for bread production. The experiment in randomized blocks with six replicates tried to clarify the interaction between twelve cultivars and seven fungicide application programs, as well as its implications in the yield and quality of wheat grains. The results showed that the effects provided by fungicides in disease control, and their direct effects on the physiology of wheat plants, were decisive factors for obtaining highquality wheat. The results also showed that diseases compromise the remobilization of nitrogen from leaves to grains. The differences between strobilurins and triazoles were evident in the control of leaf spot and leaf rust, in which triazole fungicides were more effective in controlling the leaf spot complex, when compared to strobilurins. However, effective control of wheat leaf rust was provided by strobilurins. The phenological stages of elongation and emission of spikes are critical times for the chemical control of leaf spot under conditions of monoculture. In addition, the fungicide application after flowering is essential for the appropriate management of leaf rust.

Additional keywords: gluten strength, strobilurins, nitrogen, Triticum sativum, Puccinia recondita, leaf spots.

O clima, fator preponderante no aparecimento e evolução das doenças na cultura do trigo, influencia sobremaneira o potencial de dano e o tipo de doenças que proporcionam perdas econômicas e dificultam a produção. Considerando que os invernos da região sul do Brasil são predominantemente chuvosos e com temperaturas amenas a altas, a ocorrência de ferrugem da folha do trigo (Puccinia recondita Rob. ex. Desm. f.sp. tritici Heriks. \& Henn) é bastante comum. Picinini (21) quantificou reduções de até $80 \%$ na produtividade de grãos, enquanto que Reis et. al. (23) constataram dano equivalente a 10,5 a $18,7 \mathrm{~kg} \mathrm{ha}^{-1}$ para cada $1 \%$ de incidência foliar da ferrugem.
Além da ferrugem da folha, as manchas foliares: mancha amarela [Pyrenophora tritici-repentis (Died) Drechs. (anamorfo: Drechslera tritici-repentis (Died.) Schoem.], mancha marrom [Cochliobolus sativus (Ito \& Kurib.), Drechs. ex. Dastur. (anamorfo: Bipolaris sorokiniana Sacc. in. Sorok.)], mancha da gluma [Phaeosphaeria nodorum (anamorfo: Stagonospora nodorum (Berk.) Cast \& Germ] e mancha salpicada [Septoria tritici Roberge in Desmaz. (teleomorfo: Mycosphaerella graminicola (Fuckel) J. Schöt. In Chon] são consideradas o complexo de doenças mais danoso para a cultura do trigo (14), chegando a acarretar perdas de até $80 \%$ na produtividade 
de grãos $(9,15)$.

A produtividade e a qualidade do trigo estão diretamente correlacionadas com a área foliar verde ou sadia durante o enchimento de grãos. O que faz da senescência foliar precoce, proporcionado principalmente por essas doenças, um fator que afeta seriamente o potencial produtivo do trigo (30). Portanto, o atraso da senescência foliar se torna uma característica agronômica desejável $(22,26)$. A manutenção da folha bandeira verde é particularmente importante porque é a última folha que senesce, intercepta mais luz do que as folhas mais baixas (7), e contribui com cerca de 30 a $50 \%$ dos fotoassimilados para o enchimento de grãos (27). Além de que a sua longevidade correlaciona-se estreitamente com acúmulo de proteína no grão (19).

Os fungicidas, através do controle das doenças, têm sido associados com a redução das perdas de produtividade. Principalmente devido à manutenção da vida fotossintética do dossel foliar durante o enchimento de grãos $(18,24)$, ou ainda através de efeitos diretos dos fungicidas na fisiologia da planta de trigo (8). Assim, foi desenvolvido o estudo com o objetivo de determinar o impacto do manejo químico de doenças foliares, na qualidade e produtividade de grãos do trigo.

\section{MATERIAL E MÉTODOS}

O experimento foi composto por doze cultivares de trigo, como as parcelas principais, e nestas distribuídos sete programas de aplicação de fungicidas, como as parcelas subdivididas (tabela 1). O delineamento foi o de blocos ao acaso com seis repetições no município de Cruz Alta/RS. As parcelas experimentais tinham área de $17.34 \mathrm{~m}^{2}$ onde foram realizadas as aplicações com pulverizador costal pressurizado à $\mathrm{CO}_{2}$, com barra de aplicação provida de quatro pontas do tipo jato plano duplo defletor (TTJ60 110 02) a um volume de aplicação de 204 L.ha $^{-1}$. O acompanhamento dos principais estádios fenológicos obedeceu à escala proposta por Feeks em 1940 e modificada por Large (13).

Foram avaliados, a severidade das doenças, a área foliar verde, o teor de clorofila, a porcentagem de nitrogênio foliar, a produtividade de grãos, peso de mil grãos, peso de hectolitro e força de glúten da farinha obtida. As notas de severidade foram baseadas na metodologia descrita por Peterson et. al. (20) para severidade de ferrugem e por James (10) para severidade de manchas. A partir dos dados de severidade calculou-se a área abaixo da curva de progresso de doenças (3). Os dados de área abaixo da curva de progresso das doenças e de produtividade foram utilizados para o cálculo do índice de resposta de cultivares conforme a fórmula $\{[(\mathrm{Pp}-\mathrm{Pt}) / \mathrm{Pt}) * 100)] /[(\mathrm{AACPMFt}-$ AACPMFp)/AACPMFt)*100) + (AACPFFt-AACPFFp)/ AACPFFt)*100)-100)] $\}^{*} 100$. Onde: Pp: produtividade em kg.ha-1 do programa de controle químico, Pt: produtividade em kg.ha- ${ }^{-1}$ da testemunha, AACPMFt: área abaixo da curva de progresso de manchas foliares da testemunha, AACPMFp: área abaixo da curva de progresso de manchas foliares do programa de controle, AACPFFt: área abaixo da curva de progresso de ferrugem da folha da testemunha, AACPFFp: área abaixo da curva de progresso de ferrugem da folha do programa de controle.

A área foliar verde foi estimada através de fotos digitais no software APS Assess versão 2.0 para Windows (12). O teor de clorofila foi medido de forma indireta através do medidor de clorofila Minolta SPAD 502. A porcentagem residual de nitrogênio na folha bandeira foi obtida de 60 gramas de folhas bandeira coletadas no estádio fenológico de grão duro.
A produtividade de grãos foi obtida cortando-se todas as plantas de $5.1 \mathrm{~m}^{2}$ centrais dos $17.34 \mathrm{~m}^{2}$. As amostras colhidas foram pesadas e medida a umidade, que foi ajustada a $13 \%$ para o cálculo da produtividade final em kg.ha ${ }^{-1}$. O peso de mil grãos foi obtido através de uma contagem manual e pesagem e o peso de hectolitro pesando o volume de $250 \mathrm{~mL}$ de grãos. A força de glúten foi determinada através da alveografia da farinha obtida. Todas as variáveis foram submetidas à análise de variância e o teste de comparação múltipla de médias de Tukey a 5\% no software ASSISTAT (25).

\section{RESULTADOS}

Os fungicidas, com destaque para as estrobilurinas, promoveram maior longevidade foliar e melhor utilização do nitrogênio, proporcionando maior produtividade e qualidade de grãos, assim como observado por Pepler et. al. (18) e Ruske et. al. (24). Os resultados demonstraram que as doenças comprometeram a remobilização do nitrogênio das folhas para os grãos, além das diferenças entre estrobilurinas e triazóis no controle de manchas foliares e de ferrugem da folha.

As manchas foliares nos valores médios dos doze cultivares apresentaram uma AACPD média na testemunha de 933,2. Os tratamentos mais efetivos no controle das manchas foram, três aplicações da mistura de triazol com estrobilurina e a aplicação isolada de epoxiconazol. Ambos formaram um grupo estatisticamente distinto dos demais, onde as aplicações com somente estrobilurinas foram deficientes no controle das manchas (figura 1). De acordo com Menegon et. al. (16) e o observado nestes resultados, as aplicações preventivas protegeram as plantas de novas infecções, enquanto que as aplicações curativas resultaram em lesões iniciais maiores e mais numerosas, mostrando que os fungicidas têm pouco efeito sobre a expansão das lesões.

A ferrugem da folha com uma AACPD média na testemunha de 991,8 apresentou o resultado inverso ao das manchas. A aplicação de epoxiconazol foi estatisticamente diferente dos demais, apresentando uma quantidade maior da doença (figura 1). Arduim (2) constatou menor sensibilidade aos triazóis de algumas raças de Puccinia triticina. As estrobilurinas quando aplicadas no estádio de grão aquoso, além do controle efetivo da ferrugem promoveram um "efeito verde" mostrando uma área foliar verde estatisticamente maior que os tratamentos com apenas triazol (figura 2).

O cultivar 'FCP Horizonte' apresentou a maior AACPD de manchas, seguido de 'BRS Timbaúva', 'FCP Raízes' e 'OR Pampeano'. O cultivar 'FCP 52' apresentou a maior AACPD de ferrugem, seguido de 'FCP 51, 'FCP 300' e 'FCP Nova Era'. O índice de resposta de cultivares ao controle químico apresentou os programas de controle agrupados no interior da figura para os cultivares mais suscetíveis a manchas e mais afastadas do centro para os cultivares mais suscetíveis a ferrugem, evidenciando que a ferrugem foi mais danosa do que as manchas. O que tornou os cultivares muito suscetíveis à ferrugem, mais dependentes dos fungicidas, com maior índice de resposta. Os programas de controle com aplicações antecipadas se localizaram nos discos mais exteriores para os cultivares suscetíveis a manchas e mais no interior para os cultivares suscetíveis a ferrugem, mostrando que as aplicações antecipadas se adéquam melhor ao controle de manchas, faltando-lhes mais uma aplicação após o florescimento para serem efetivas contra a ferrugem (figura 3). Portanto, a efetividade de controle de doenças foliares na cultura do trigo esta em impedir novas infecções (aplicações antecipadas) para manchas foliares, sendo necessário proteger a folha da ferrugem após o florescimento. 

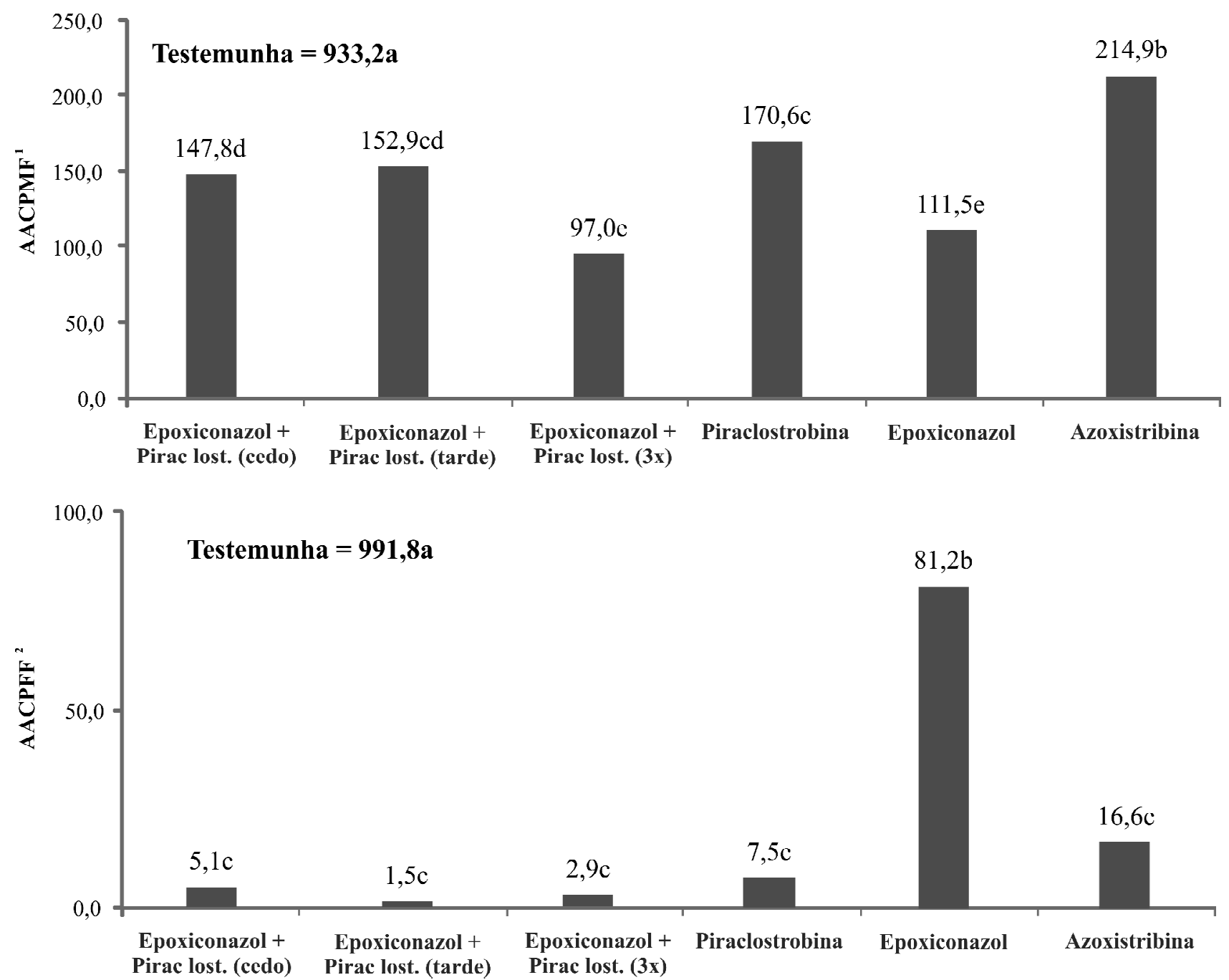

Figura 1. Área abaixo da curva de progresso de doenças (AACPD) para os programas de controle químico aplicados em doze cultivares de trigo. Cruz Alta $-\mathrm{RS} / 2010$.

*médias seguidas de mesma letra não diferem entre si pelo teste te Tukey $\mathrm{p}<0,05$. $^{1} \mathrm{AACPMF}=\mathrm{AACPD}$ de Manchas Foliares. ${ }^{2} \mathrm{AACPFF}=\mathrm{AACPD}$ de Ferrugem da Folha.

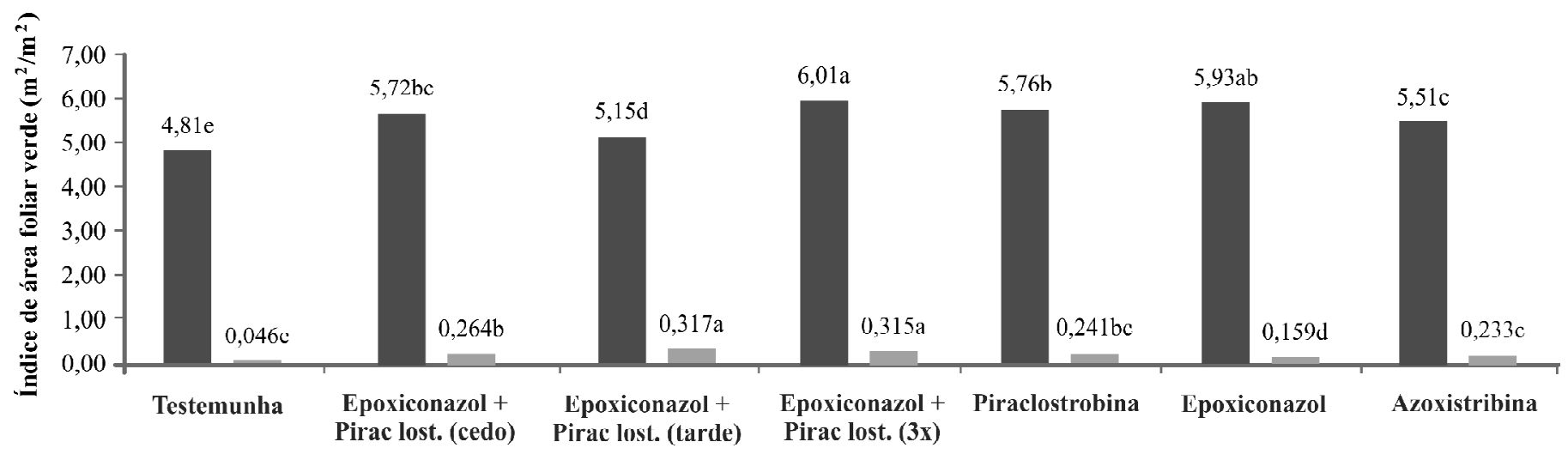

— Índice de área foliar no Florescimento (10.5.3) — Índice de área foliar no Grãos massa mole (11.2)

Figura 2 - Área foliar verde para os programas de controle químico aplicados em doze cultivares de trigo. Cruz Alta - RS/2010.

*médias seguidas de mesma letra não diferem entre si pelo teste te Tukey $\mathrm{p}<0,05$. 
Os tratamentos proporcionaram não só um aumento significativo de produtividade, mas também na qualidade dos grãos produzidos (peso de mil grãos, peso hectolitro e força de glúten). Os dois cultivares mais produtivos ('OR Quartzo' e 'FCP Horizonte') foram os mais influenciados pelos efeitos dos fungicidas. Notadamente a aplicação de piraclostrobina, apesar de não ter controlado efetivamente as manchas, proporcionou os maiores valores de força de glúten e peso de mil grãos nestes cultivares, independente desta estar ou não associada ao epoxiconazol. Contudo, o tratamento de epoxiconazol isolado também proporcionou altos valores de força de glúten, devido a efetividade no controle das manchas. Os dados mostraram que houve maior remobilização do nitrogênio das folhas para os grãos nestes tratamentos (porcentagem de $\mathrm{N}$ foliar vs. força de glúten em relação as testemunhas) (tabela 1).

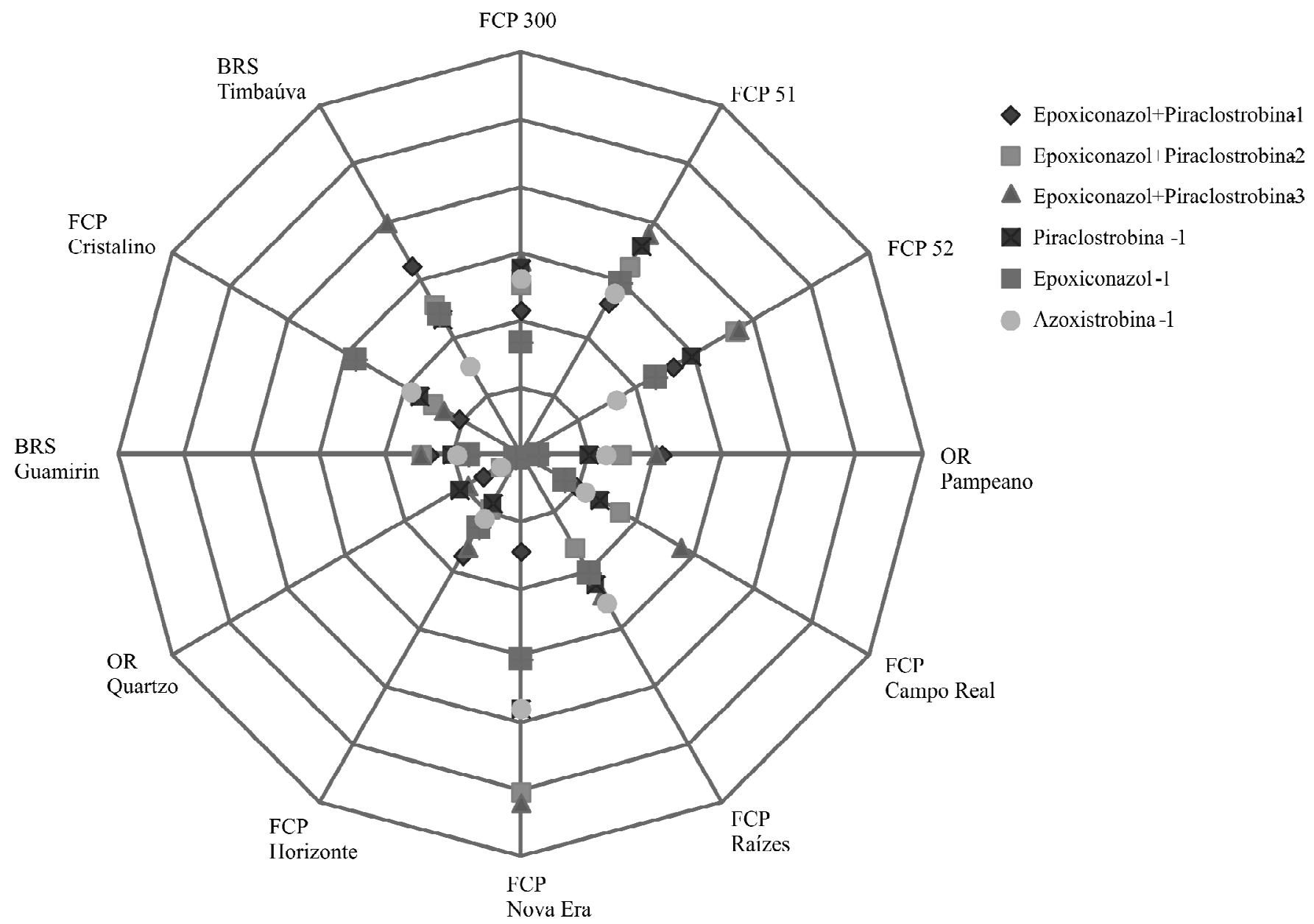

Figura 3. Índice de resposta de cultivares calculado para a interação entre os doze cultivares e os seis programas de controle. Cruz Alta - RS/2010.

Tabela 1. Relação dos cultivares utilizados no experimento, suas características agronômicas e reação às doenças apresentadas no local do experimento. Cruz Alta $-\mathrm{RS} / 2010$.

\begin{tabular}{|c|c|c|c|c|c|}
\hline Cultivares & Ciclo(dias) & Estatura & Classe Comercial & Reação a Ferrugem da Folha & Reação a Manchas Foliares ${ }^{1}$ \\
\hline FCP 300 & Médio(142) & Média/Baixa & Brando & Suscetível & Moderada Resistência \\
\hline FCP 51 & Médio/Tardio(147) & Alta & Brando & Suscetível & Moderada Resistência \\
\hline FCP 52 & Precoce(137) & Baixa & Brando & Suscetível & Moderada Resistência \\
\hline OR Pampeano & Precoce(136) & Média & Brando & Moderada Resistência & Moderada Suscetibilidade \\
\hline FCP Campo Real & Precoce(136) & Baixa & Brando (branqueador) & Suscetível & Moderada Suscetibilidade \\
\hline FCP Nova Era & Médio/Tardio(147) & Média/Baixa & Brando & Suscetível & Moderada Resistência \\
\hline FCP Horizonte & Precoce(137) & Média & Pão (branqueador) & Resistente & Suscetível \\
\hline OR Quartzo & Médio(145) & Média & Pão & Moderada Suscetibilidade & Moderada Resistência \\
\hline BRS Guamirin & Precoce(137) & Baixa & Pão & Moderada Resistência & Moderada Resistência \\
\hline FCP Cristalino & Precoce(136) & Média & Melhorador & Moderada Resistência & Moderada Suscetibilidade \\
\hline
\end{tabular}

${ }^{1}$ Dados fornecidos pelos obtentores dos cultivares. 
Tabela 2. Programas de controle químico aplicados nos doze cultivares trigo. Cruz Alta - RS/2010.

\begin{tabular}{|c|c|c|c|}
\hline Fungicidas & Dose i.a.ha ${ }^{-1}(g)$ & Dose p.c.ha ${ }^{-1}$ (L) & Estádios de Aplicação \\
\hline Epoxiconazol + Piraclostrobina ${ }^{1}$ & $50+133$ & 1,0 & Elongamento $(7)>$ Florescimento $(10.5 .2)$ \\
\hline Epoxiconazol + Piraclostrobina & $50+133$ & 1,0 & Emborrachamento (9) > Grão Aquoso (10.5.4) \\
\hline Epoxiconazol + Piraclostrobina & $50+133$ & 1,0 & 1 nó (6) > Emborrachamento (9) > Grão Aquoso (10.5.4) \\
\hline Piraclostrobina ${ }^{2}$ & 100 & 0,4 & Elongamento $(7)>$ Florescimento $(10.5 .2)$ \\
\hline Epoxiconazol $^{3}$ & 100 & 0,8 & Elongamento $(7)>$ Florescimento $(10.5 .2)$ \\
\hline Azoxistrobina ${ }^{4}$ & 100 & 0,4 & Elongamento $(7)>$ Florescimento $(10.5 .2)$ \\
\hline
\end{tabular}

${ }^{1}$ Opera $183 \mathrm{SE} ;{ }^{2}$ Comet $250 \mathrm{EC} ;{ }^{3} \mathrm{Opus} 125 \mathrm{SC} ;{ }^{4}$ Priori $250 \mathrm{SC}$

Tabela 3. Médias das variáveis agronômicas avaliadas para os programas de controle químico aplicados em doze cultivares de trigo. Cruz Alta - RS/2010.

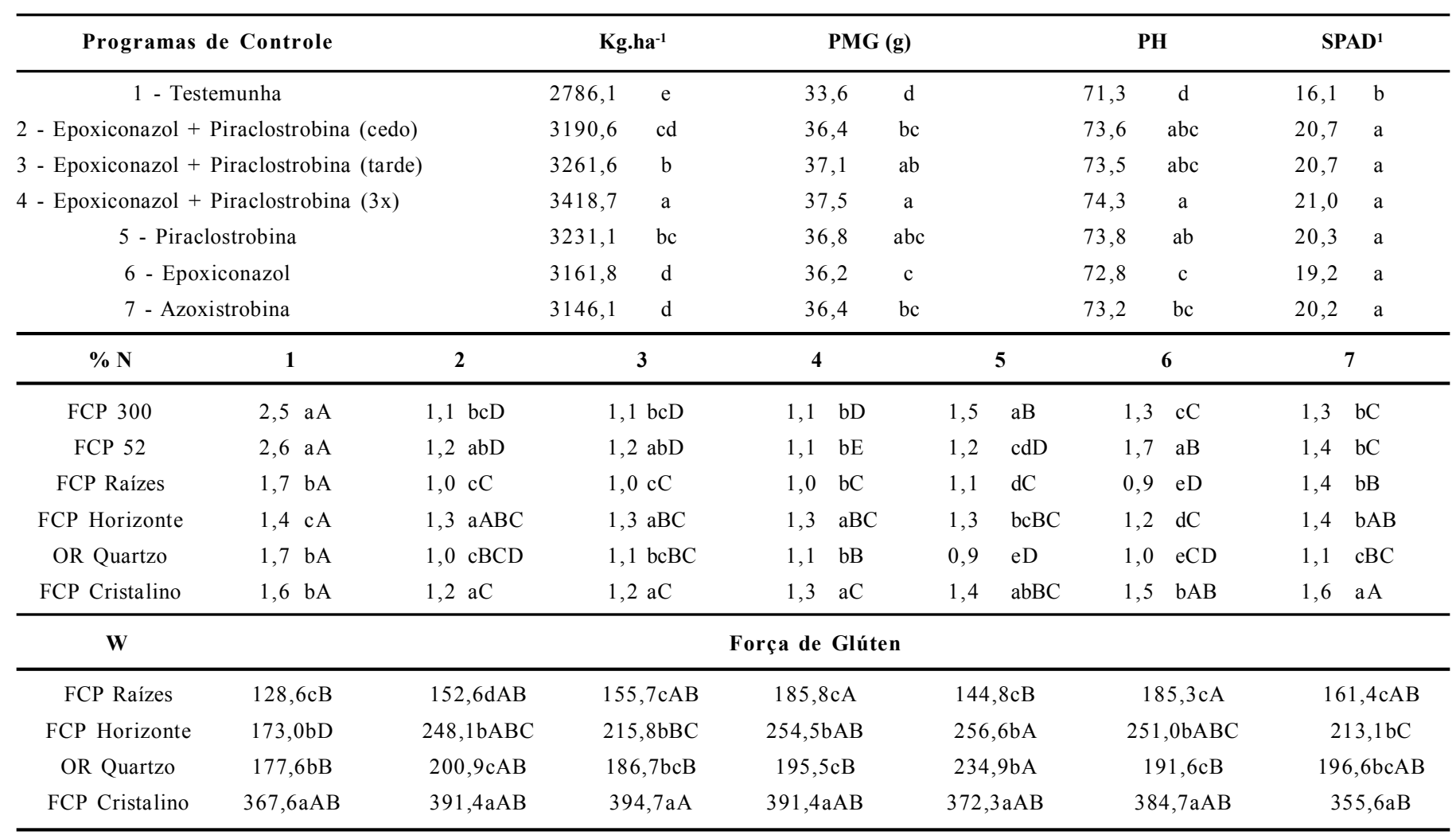

*letras maiúsculas classificam linhas e letras minúsculas classificam colunas pelo teste de Tukey $\mathrm{p}<0.05$.

${ }^{1}$ SPAD $=$ teor de clorofila medido pelo aparelho Minolta SPAD 502 no estádio de grão duro.

A literatura lista vários processos interdependentes envolvidos no efeito fisiológico das estrobilurinas, entre os principais estão o aumento na atividade da enzima nitrato redutase e aumento na fotossíntese líquida $(5,6,8,11,29)$. Aliado a isso Walters $(28)$ relatou acúmulo significativo de nitrogênio dentro de pústulas de $P$. graminis em folhas de trigo, o mesmo foi observado (tabela 1). Os cultivares 'FCP 300' e 'FCP 51' infectados por ferrugem apresentaram níveis elevados de nitrogênio foliar remanescente no estádio de grão duro nas testemunhas. Controlando a ferrugem diminuiu-se a concentração, proporcionando maiores valores de força de glúten e aumento nos teores de clorofila nos tratamentos fungicidas $(1,17)$. Portanto, a infecção por Puccinia spp. pode ser mais prejudicial para o acúmulo de nitrogênio nos grãos do que no acúmulo de matéria seca (4).

O cultivar 'FCP Horizonte' (resistente a ferrugem da folha) que apresentou alta produtividade com altos índices de manchas foliares, mostrou uma alta capacidade de remobilizar o nitrogênio das folhas, mesmo que doentes, para os grãos, apresentando diferenças menores na porcentagem de nitrogênio foliar entre testemunha e tratado, em relação aos demais cultivares. Porém com diferença significativa para os valores de força de glúten.

Os cultivares suscetíveis a ferrugem apresentaram mais dificuldade na remobilização do nitrogênio das folhas para os grãos. A estratégia biotrófica de infecção da ferrugem promoveu maior imobilização do nitrogênio na folha quando comparada as manchas. Por fim, os cultivares de trigo pão muito suscetíveis a ferrugem da folha necessitam mais dos fungicidas para que o nitrogênio vá das folhas para os grãos. Enquanto que os cultivares de trigo pão muito suscetíveis a manchas foliares necessitam dos fungicidas para potencializar a produtividade, apresentando maior estabilidade na obtenção de trigo com qualidade para panificação.

$\mathrm{O}$ uso de fungicidas evita perdas de produtividade e qualidade provocadas pelas doenças foliares na cultura do trigo. Os fungicidas triazóis são mais eficientes no controle do complexo de manchas foliares, quando comparados as estrobilurinas. Entretanto, o controle 
efetivo da ferrugem da folha do trigo se deve a ação das estrobilurinas, a menor sensibilidade de raças de Puccinia triticina aos triazóis compromete sua efetividade.

Os estádios fenológicos do elongamento e emissão de espigas são momentos críticos para o posicionamento ideal do controle químico de manchas foliares em condições de monocultura, e a aplicação de fungicidas após o florescimento é imprescindível para o adequado manejo da ferrugem da folha visando obtenção de trigo com qualidade para panificação. Por fim, as estrobilurinas promovem melhor remobilização do nitrogênio das folhas para os grãos, apresentando aumento significativo na força de glúten e menor porcentagem de nitrogênio foliar remanescente.

\section{REFERÊNCIAS BIBLIOGRÁFICAS}

1. Abdel-Hak, T. et al. Evaluation of fungicides for the control of yellow stripe rust of wheat. Egyptian Journal of Phytopathology, Orman, v. 19, p. 85-96, 1987.

2. Arduim, G.S. Sensibilidade de raças de Puccinia triticina a fungicidas. 2009. $91 \mathrm{f}$. Tese (Doutorado em Fitopatologia) Faculdade de Agronomia e Medicina Veterinária - Universidade de Passo Fundo, Passo Fundo.

3. Campbell, C.L.; Madden, L.V. Introduction to plant disease epidemiology. New York: J. Wiley, 1990. cap.6, p.107-128.

4. Dimmock, J. P. R. E.; Gooding, M. J. The effects of fungicides on rate and duration of grain filling in winter wheat in relation to maintenance of flag leaf green area. The Journal of Agricultural Science, Cambridge, v. 138, n.1, p. 1-16, Feb. 2002.

5. Fagan, E. B. A cultura de soja: modelo de crescimento e aplicação da estrobilurina piraclostrobina. 2007. 84 f. Tese (Doutorado em Fisiologia) - Escola Superior de Agricultura Luiz de Queiroz, Piracicaba.

6. Glaab, J.; Kaiser, W. M. Increased nitrate reductase activity in leaf tissues after application of the fungicide Kresoxim-methyl. Planta, Berlin, v. 207, p.442-448, 1999.

7. Gooding, M. J. et al. Green leaf area decline of wheat flag leaves: the influence of fungicides and relationships with mean grain weight and grain yield. Annals of Applied Biology. London, v. 136, p. 77-84, 2000.

8. Grossmann, K.; Retzlaff, G. Bioregulatory effects of the fungicidal strobilurin kresoxim methyl in wheat (Triticum aestivum L.). Pesticide Science, Oxford, v. 50, p. 11-20, 1997.

9. Hetzler, J. et al. Interaction between Cochliobolus sativus and wheat cultivars. In: International conference on wheat for nontraditional warmer areas, 1991, México D.F.. Proceedings. Mexico D.F.: Cimmyt, 1991. p.146-164.

10. James, C. An illustrated series of assessment keys for plant diseases, their preparation and usage. Com. Plant. Dis. Surv. v. 51, p. 2, 1971 .

11. Köehle, $H$. et al. Physiological effects of the strobilurin fungicide F500 on plants. In: Dehne, H.-W.; Gisi, U.; Kuck, K.H.; Russel, P.E.; LYR, H. (Eds.) Modern fungicides and antifungal compounds III. Andover, DPG Spectrum Phytomedizin, 2002, p. 61-74.

12. Lamari, L. Assess 2.0: image analysis software for plant disease quantification. St. Paul: APS Press, 2002. 1 CD-ROM.

13. Large, E. C. Growth stages in cereals. Illustration of the Feekes scale. Plant Pathology, Oxford, v. 3, n. 4, p. 128-129, 1954.

14. Mehta, Y. R. et al. Integrated management of major wheat diseases in Brazil: an example for the Southern Cone region of Latin
America. Crop Protection, New York, v. 11, n. 6, p. 517-524, Dec. 1992.

15. Mehta, Y. R. Manejo integrado de enfermedades del trigo Santa Cruz de la Sierra: Imprenta Landivar, 1993. 314 p.

16. Menegon, A.P. et al. Expansão de lesão da mancha-reticular da cevada e sua interação com o tratamento de sementes. Fitopatologia Brasileira, Viçosa, 30:139-142. 2005.

17. Park, R. F.; Rees, R. G.; Platz, G. J. Some effects of stripe rust infection in wheat with adult plant resistance. Australian Journal of Agricultural Research, Victoria, v. 39, p. 555-562, 1998.

18. Pepler, S. et al. A temporal limit to the association between flag leaf life extension by fungicides and wheat yields. European Journal of Agronomy, Copenhagen, v. 22, n. 4, p. 363-373, May 2005.

19. Pepler, S. et al. Delaying senescence of wheat with fungicides has interacting effects with cultivar on grain sulphur concentration but not with sulphur yield or nitrogen:sulphur ratios. European Journal of Agronomy, Copenhagen, v. 22, n. 4, p. 405-416, May 2005.

20. Peterson, R. F.; Campbell, A. B.; Hannah, A. E. A diagrammatic scale for estimating rust intensity of leaves and stem of cereals. Canadian Journal Research C, Ottawa, v. 26, p. 496-500, 1948.

21. Picinini, E. C. Estratégias no manejo de enfermidades e proteção química de cereais de inverno. K In: Kohli, M. M., Anone, J. G. Garcia, R. (Eds.) Curso de manejo de enfermedades del trigo. Buenos Aires: CIMMYT, Estación Experimental Agropecuaria INTA Pergamino, 1995. p. 35-52.

22. Quirino, B. F. et al. Molecular aspects of leaf senescence. Trends Plant Science, Oxford, v. 5, p. 278-282, 2000.

23. Reis, E. M. et al. Effect of leaf rust on wheat brain yield. Fitopatologia Brasileira, Brasilia D.F., v. 25, n. 1, p. 67-71, jan./mar. 2000 .

24. Ruske, R. E. et al. The effects of triazole and strobilurin fungicide programmes on nitrogen uptake, partitioning, remobilization and grain $\mathrm{N}$ accumulation in winter wheat cultivars. The Journal of Agricultural Science, Cambridge, v. 140, n. 4, p. 395-407, June 2003.

25. Silva, F. de A. S. e.; Azevedo, C. A. V. de. principal components analysis in the software assistat-statistical attendance. In: World congress on computers in agriculture 7, 2009, Proceedings, Reno: American Society of Agricultural and Biological Engineers, 2009.

26. Subhan, D.; Murthy, S. D. S. Senescence retarding effect of metal ions: pigment and protein contents and photochemical activities of detached primary leaves of wheat. Photosynthetica, Prague, v. 39 , n. 1 , p. 53-58, Jan./Mar. 2001.

27. Sylvester-Bradley, R.; Scott, R. K.; Wright, C. E. Physiology in the production and improvement of cereals. London: HGCA, 1990 (Home-Grown Cereals Authority Research Review, v. 18).

28. Walters, D. R. Phosphorous and nitrogen fluxes between plant and fungus in parasitic associations. In: Boddy, L.; Marchant, R.; Read, D. J. (Ed.). Nitrogen, phosphorus and sulphur utilisation by fungi. Cambridge: Cambridge University Press, 1989. p. 131-154.

29. Ypema, H. L.; Gold, R. E. KRESOXIM-METHYL: Modification of a Naturally Occurring Compound to Produce a new Fungicide. Plant Disease, Saint Paul, v. 83, n. 1, p. 4-19. Jan. 1999.

30. Zhang, C. J. et al. Photosynthetic decline in flag leaves of two field-grown spring wheat cultivars with different senescence properties. South African of Journal Botany, Scottsville, v. 72, n. 1, p. 15-23, Jan./Feb. 2006. 